\title{
CORRELATION BETWEEN STRUCTURE AND MAGNETIC PROPERTIES OF "FINEMET" TYPE MICROWIRES
}

\author{
Kutseva N.A., Bashev V.F., Ryabtsev S.I., Krapivina-Soloviova O.S. \\ Oles Honchar Dnipro National University, Dnipro, Ukraine \\ e-mail: kutseva.natalia@gmail.com
}

Effect of geometrical parameters (metallic core diameter, glass cover thickness) on the structure and magnetic properties of glass-coated $\mathrm{Fe}-\mathrm{Si}-\mathrm{B}-\mathrm{Nb}$-Cu microwires is investigated. The structure of as-prepared $\mathrm{Fe}_{73.8} \mathrm{Cu}_{1} \mathrm{Nb}_{3.1} \mathrm{Si}_{13} \mathrm{~B}_{9.1}$ microwire is nanocrystalline, consisting of $\alpha-\mathrm{Fe}(\mathrm{Si})$ crystallites in a residual amorphous matrix. It is shown that great residual stresses arising at the manufacturing processes greatly influence the microstresses and crystallite sizes of $\alpha-\mathrm{Fe}(\mathrm{Si})$ crystals. An increasing of stress magnitude results to structure refinement. The size of $\alpha-\mathrm{Fe}(\mathrm{Si})$ crystals and crystallized volume fraction decrease from approximately $105 \mathrm{~nm}$ and $71 \%$ to $9 \mathrm{~nm}$ and $34 \%$, respectively, with glass cover thickness increasing. Grain size refinement of $\alpha-\mathrm{Fe}(\mathrm{Si})$ leads to the considerable decrease of coercivity of microwires from $1800 \mathrm{~A} / \mathrm{m}$ to $160 \mathrm{~A} / \mathrm{m}$.

Keywords: microwire, nanocrystalline structure, stresses, magnetic properties, X-ray diffraction.

Received 03.11.2019; Received in revised form 15.12.2019; Accepted 23.12.2019

\section{Introduction}

The outstanding soft magnetic properties (the large Barkhausen (LBE) effect, giant magnetoimpedance (GMI) effect, low coercivity) of amorphous and nanocrystalline microwires (MW) obtained by the Taylor-Ulitovsky method make them attractive as sensor elements in a large variety of miniature electronic devices [1]. New Fe-based alloys with additions of $\mathrm{Cu}$ and $\mathrm{Nb}$ with trademark "Finemet" have been developed. $\mathrm{Cu}$ additions have a tendency to segregate from atoms $\mathrm{Fe}$ and affect the nucleation of a great number of new embryos of grains. $\mathrm{Nb}$ additions have effect of raising the crystallization temperature. It is known that crystallization processes in Finemet type microwires play a decisive role in improving their soft magnetic properties and GMI effect [2,3]. Excellent magnetic properties in such materials are achieved by the formation of a nanocrystalline structure, which consists of $\alpha-\mathrm{Fe}(\mathrm{Si})$ nanocrystals surrounded by an amorphous matrix. On the one hand, the TaylorUlitovsky method allows increasing the degree of undercooling of melt due to nonequilibrium crystallization on a neutral substrate, but on the other hand, one of the features of the microwire production method is the presence of large internal stresses: axial tension stresses and quenching stresses induced during the rapid solidification of the microwire and stresses induced by glass coating. The difference in the coefficients of thermal expansion of glass and metal (more than 10 times) is responsible for high radial stresses that are maximal at the metal core surface and decrease toward the wire axis. The magnetic domain structure of MW with a positive saturation magnetostriction consists of a large single domain magnetized along the microwire axis and surrounded by an outer shell with the magnetization oriented in the radial direction [4].

Most recent publications are focused on the influence of the fabrication methods, geometric characteristics, and appropriate heat treatment on the magnetic properties of these materials [5], while little attention is paid to the influence of technological parameters on the structure of MW. In this work we study the influence of geometrics parameters on the structure and magnetic properties of Finemet type microwires.

\section{Experimental details}

Initial glass-coated microwires of nominal composition $\mathrm{Fe}_{73.8} \mathrm{Cu}_{1} \mathrm{Nb}_{3.1} \mathrm{Si}_{13} \mathrm{~B}_{9.1}$ with different geometric characteristics (diameter of the metallic core, total wire diameter, glass cover) were obtained by the Taylor-Ulitovsky method (Table 1). According to the calculations, the cooling rate of investigated MW was approximately $10^{6} \mathrm{~K} / \mathrm{s}$. 
Geometrical parameters of initial microwires

\begin{tabular}{|c|c|c|c|c|}
\hline $\mathrm{N}$ & $\begin{array}{c}\text { Metallic core diameter } \\
\mathrm{d}, \mu \mathrm{m}\end{array}$ & $\begin{array}{c}\text { Total diameter of MW } \\
\mathrm{D}, \mu \mathrm{m}\end{array}$ & $\mathrm{d} / \mathrm{D}$ & $\begin{array}{c}\text { Glass cover thickness, } \\
\mathrm{tgl}, \mu \mathrm{m}\end{array}$ \\
\hline 1 & 15.8 & 29.4 & 0.54 & 6.8 \\
\hline 2 & 17.8 & 29.6 & 0.60 & 5.9 \\
\hline 3 & 14.2 & 21.6 & 0.66 & 3.7 \\
\hline 4 & 16.0 & 23.0 & 0.69 & 3.5 \\
\hline 5 & 18.8 & 25.0 & 0.75 & 3.1 \\
\hline
\end{tabular}

The structure investigations of MW were carried out by using X-ray diffraction (Mo $\mathrm{K}_{\alpha}$ radiation, $\lambda=0.71 \mathrm{~nm}$ ). The samples were attached to the diffractometer sample holder at which each scan was made over the $2 \theta$ angular range from 10 to $120^{\circ}$, step size of $01^{\circ}$, step time of $100 \mathrm{~s}$ for each step. The heat treatments were performed in a conventional furnace. Magnetic properties of MW were measured by means of a conventional induction method at $50 \mathrm{~Hz}$.

\section{Results and discussion}

The X-ray diffraction patterns show that initial microwires have nanocrystalline structure. XRD spectra consist of reflections related to the $\alpha-\mathrm{Fe}(\mathrm{Si})$ crystallites and amorphous phase. Dependence of the structure characteristics of MW on geometrical parameters is presented in Fig. 1 and Table 2.
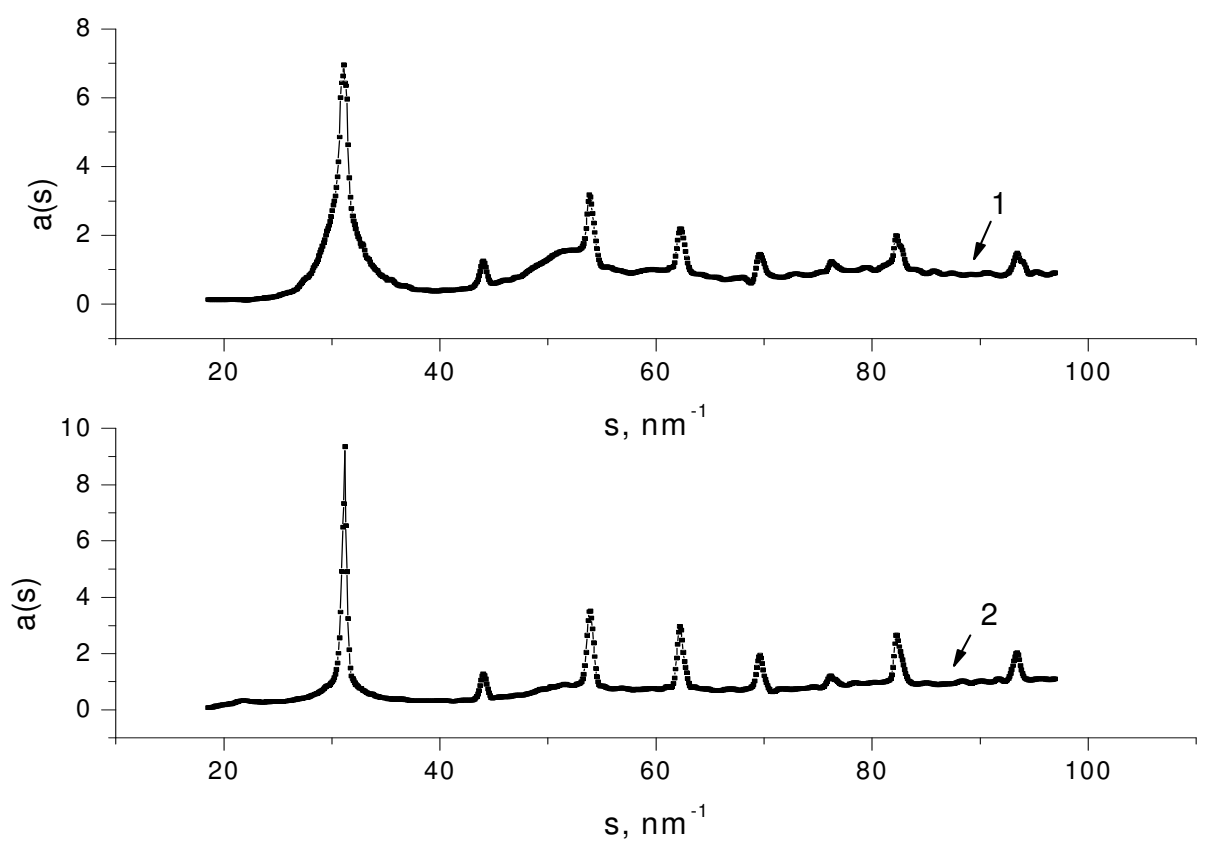

Fig. 1. Structure factors of initial MW: $1-\mathrm{d} / \mathrm{D}=0.54, \mathrm{t}_{\mathrm{gl}}=6.8 \mu \mathrm{m} ; 2-\mathrm{d} / \mathrm{D}=0.75, \mathrm{t}_{\mathrm{gl}}=3.1 \mu \mathrm{m}$.

It can be seen (Fig. 1), with increasing the glass insulation thickness the interference maxima become broaden and the position of the second diffusive halo is clearer fixed in the intervals $50-60 \mathrm{~nm}^{-1}$. 
The parameters of short-range order of initial MW were calculated by the method described in $[6,7]$. The integral breadth and crystallized volume fraction $\left(\mathrm{X}_{\mathrm{c}}\right)$ were evaluated by the deconvoluting the total profile of the amorphous halo and the (110) peak of $\alpha-\mathrm{Fe}(\mathrm{Si})$ crystallites. The profile of the main diffraction peak was fitted by pseudoVoigt function. The mean grain size of the crystals is derived from the Scherrer equation.

Structure parameters of as-prepared MW with different ratios d/D

Table 2

\begin{tabular}{|c|c|c|c|c|c|c|c|c|c|c|}
\hline$N$ & $\mathrm{~s}_{1}, \mathrm{~nm}^{-1}$ & $\mathrm{i}\left(\mathrm{s}_{1}\right)$ & $\mathrm{r} 1, \mathrm{~nm}$ & $\mathrm{~A}_{\mathrm{m}}$ & $\mathrm{X}_{\mathrm{c}}$ & $\mathrm{a}, \mathrm{nm}$ & $\beta_{2} / \beta_{1}$ & $\begin{array}{c}\mathrm{D}_{110}, \\
\mathrm{~nm}\end{array}$ & $\frac{\Delta \mathrm{a}}{\mathrm{a}}, 10^{-3}$ & $\sigma, \mathrm{GPa}$ \\
\hline 1 & 31.1 & 6.9 & 0.250 & 12.2 & 0.34 & 0.2857 & 0.8 & 9 & - & -1.73 \\
\hline 2 & 31.3 & 7.2 & 0.247 & 12.3 & 0.42 & 0.2855 & 0.92 & 12 & - & -1.36 \\
\hline 3 & 31.2 & 7.3 & 0.248 & 12.6 & 0.48 & 0.2854 & 1.52 & 23 & 3.2 & -1.03 \\
\hline 4 & 31.1 & 8.8 & 0.247 & 12.6 & 0.6 & 0.2852 & 1.86 & 95 & 2.5 & -0.66 \\
\hline 5 & 31.2 & 9.3 & 0.247 & 12.9 & 0.71 & 0.2852 & 1.9 & 105 & 2 & -0.66 \\
\hline
\end{tabular}

where $\mathrm{S}_{1}$ and $\mathrm{i}\left(\mathrm{S}_{1}\right)$ are the position and height of the first maximum of the structural factor, respectively; $\mathrm{r}_{1}$ is the most probable interatomic distance (the first peak position); $\mathrm{A}_{\mathrm{m}}$ is a coordination number (the area under the first maximum of the total radial distribution function of atoms); $X_{c}$ is crystallized volume fraction of $\alpha$ $\mathrm{Fe}(\mathrm{Si})$ crystallites; $\mathrm{a}$ is the lattice parameter of $\alpha-\mathrm{Fe}(\mathrm{Si})$ crystallites; $\beta_{1}$ and $\beta_{2}$ are integral breadth (integral intensity/maximum intensity) of (110) and (220) peaks of $\alpha-\mathrm{Fe}(\mathrm{Si})$ crystallites, respectively; $\mathrm{D}_{110}$ is crystallite size; $\frac{\Delta \mathrm{a}}{\mathrm{a}}$ is microstress; $\sigma$ is macrostress measured by the $\mathrm{X}$-ray analusis.

From these data it is clear, that the position of the first maximum of the structural factor changes insignificantly for all investigated MW while its height and crystallized volume fraction $\left(X_{c}\right)$ significantly increase (from $X_{c}=34 \%$ to $X_{c}=71 \%$ ) with the decreasing of the glass insulation thickness. As noted above, residual stresses play a key role in formation of structure and physical properties of MW. Depending on the length scale over which the residual stresses act relative to the microstructure, they may be defined as either macrostresses (stresses of the first kind) or microstresses (stresses of the second or third kinds). Microstresses were measured by the X-ray broadening technique. The crystal structure parameters (microstresses $\frac{\Delta \mathrm{a}}{\mathrm{a}} 220$ and crystallite sizes $\mathrm{D}_{110}$ ) were calculated by the comparing the broadening of the (110) and (220) peaks of $\alpha-\mathrm{Fe}(\mathrm{Si})$ crystallites. It was found (Table 2) that for MW $(1,2)$ the broadening of interference peaks is due to only the crystallite smallness (the grain size of $\alpha-\mathrm{Fe}(\mathrm{Si})$ crystallites is $9-12$ $\mathrm{nm})$. For MW (3-5), the peak broadening is caused by both the presence of microstresses and the crystallite smallness. As mentioned above, significant quenching stresses (macrostresses) occur in the wire during manufacturing process. Residual stresses (stresses induced by the solidification of MW and stresses induced due to the difference of the thermal expansion coefficients of a metal core and glass) were calculated in [8]. According to the calucations, the stresses induced due to the difference of the thermal expansion coefficients of the metal core and glass were the most significant and reached $\sim 1 \mathrm{GPa}$. On the other hand, macrostresses can be calculated using X-ray analysis by measuring the changes in the lattice parameters of stressed and unstressed MW. The values of the macrostresses are presented in Table 2. From these data it is clear that the magnitude of macrostresses changes by 2.5 times with the increase of insulation thickness of MW. It can be concluded that such significant stresses can lead to the grain size refinement of $\alpha-\mathrm{Fe}(\mathrm{Si})$ crystallites and formation of a more nonequilibrium structure of MW. The great residual stresses due to macrostresses determine its magnetic properties. Dependence of coercivity of MW on the glass cover thickness is presented in Fig. 2. Glass cover thickness increasing leads to the formation of more nonequilibrium structure 


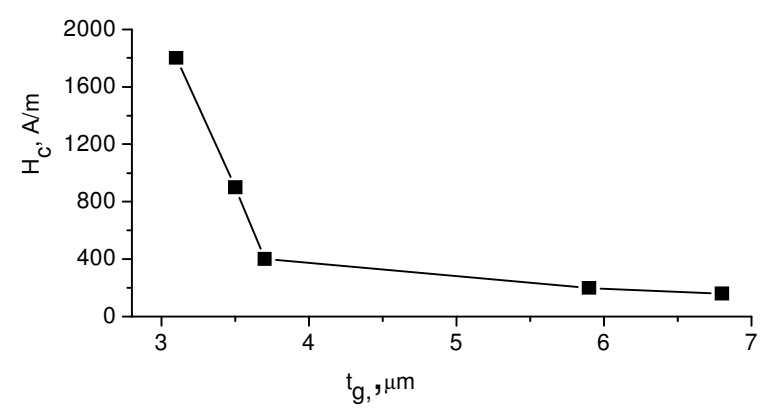

Fig. 2. Dependence of coercivity of MW on the glass cover thickness.

and causes a decrease of the coercivity of MW from $1800 \mathrm{~A} / \mathrm{m}$ to $160 \mathrm{~A} / \mathrm{m}$.

\section{Conclusions}

In paper was found that initial $\mathrm{Fe}_{73.8} \mathrm{Cu}_{1} \mathrm{Nb}_{3.1} \mathrm{Si}_{13} \mathrm{~B}_{9.1}$ glass-coated microwires have nanocrystalline structure consisting of $\alpha-\mathrm{Fe}(\mathrm{Si})$ crystallites in a residual amorphous matrix. It is shown that an increase of glass insulation thickness of MW leads to the grain size refinement and decrease of crystallized volume fraction of $\alpha-\mathrm{Fe}(\mathrm{Si})$ crystallites from $105 \mathrm{~nm}$ and $71 \%$ to $9 \mathrm{~nm}$ and 34\%, respectively. The macrostress values prove to be strongly dependent on geometrical parameters of MW. It is established that magnetic properties dramatically changed from $1800 \mathrm{~A} / \mathrm{m}$ to $160 \mathrm{~A} / \mathrm{m}$ due to the formation of a more nonequilibrium structure.

\section{References}

1. Zhukov, A. Development of Thin Magnetic Amorphous Microwires for High Frequency Magnetic Sensors Applications / A. Zhukov, M. Ipatov, C. García, J. Gonzalez, L. Panina, J.M. Blanko, V. Zhukova // Progress in Electromagnetics Research Symposium, Hangzhou, China, March, 2008. - P. 650 - 657.

2. Talaat, A. Magnetic properties of nanocrystalline microwires / A. Talaat, V. Zhukova, M. Ipatov, J.M. Blanco, R. Varga, P. Klein, L. Gonzalez-Legarreta, B. Hernando, A. Zhukov // J. of Electronic Materials. - 2016. - Vol. 45, No. 1. - P. 212 - 218.

3. Serrano, I.G. Low temperature magnetic behaviour of glass-covered magnetic microwires with gradient nanocrystalline microstructure / I.G. Serrano, A. Hernando, P. Marin // J. Appl. Phys. - 2014. - Vol. 115. - P. 033903(7).

4. Orlova, N.N. Magnetic structure and magnetization process of the glass-coated Fe-based amorphous microwire / N.N. Orlova, A.S Aronin, S.I. Bozko, Yu.P. Kabanov, V.S. Gornakov // J. of Applied Physics. - 2012. - Vol. 111. - P. 073906 (7).

5. Hernando, B. Magnetic domain structure of amorphous $\mathrm{Fe}_{73.5} \mathrm{Si}_{13.5} \mathrm{~B}_{9} \mathrm{Nb}_{3} \mathrm{Cu}_{1}$ wires under torsional stress / B. Hernando, M.L. Sanchez, V.M. Prida, J.D. Santos, J. Olivera, F.J. Belzunce, G. Badini, M. Vazquez // J. Appl. Phys. - 2008. - Vol. 103. P. 07E716(3).

6. Skrushevskiy, A.F. Strukturnyi analiz zhidkostey i amorfnykh tel. M.: Vysshaya shkola, 1980. $-328 \mathrm{p}$.

7. Kutseva, N.A. Effect of annealing on structure and magnetic properties of FeCorich amorphous glass-coated microwires / N.A. Kutseva, V.V. Delov, N.A. Tolstova, V.S. Larin // Visnyk Dnipropetrovskoho universytetu. Fizika. Radioelektronika. - 2017. - Vol. 25, Issue 24. - P. $85-57$.

8. Chiriac, H. Amorphous glass-covered magnetic wires: preparation, properties, applications / H. Chiriac, T.A. Ovari // Progress in Materials Science. - 1996. - Vol. 40. P. $333-407$. 